\section{MS31-O2 Intra- and inter-molecular interactions for the understanding of stereoselective catalytic properties of chiral metal complexes}

Fernando J. Lahoz ${ }^{1}$, Daniel Carmona ${ }^{1}$, Pilar Lamata ${ }^{1}$, Pilar García-Orduña ${ }^{1}$, Ricardo Rodríguez ${ }^{1}$, Luis A. Oro ${ }^{1}$

1. Institute for Chemical Synthesis and Homogeneous Catalysis (ISQCH), University of Zaragoza-CSIC, C/ Pedro Cerbuna, 12, 50009 Zaragoza, Spain

email: lahoz@unizar.es

Most of the physical properties of molecular complexes depend on the intramolecular bonding system established in the discrete molecule, that could be ascertained through structural analysis. In the case of catalytic properties, even for homogeneous processes, the structural information emanated from X-ray studies could give significant information on interatomic interactions, in most cases a basic knowledge to understand activity and (stereo)selectivity.

The use of Lewis acids, based on metal complexes, as catalysts for the synthesis of highly demanded enantiopure compounds has been identified as one of the most versatile method, as their activity and selectivity could be well modulated through the modification of the metal center and its ancillary ligands. In the recent past, we have been studying a family of metal catalysts containing different P,P-, N,N- y P,O- donor ligands, for which we have established that their physical properties, in particular their stereoselectivity, are closely related to the presence of subtle intra-molecular interactions.

In fact, a systematic study of a family of complexes of the type $\left[\left(\eta^{\mathrm{n}} \text {-ring }\right) \mathrm{M}(\mathrm{PP} *)(\text { substrate })\right]^{+\mathrm{n}}\left({ }^{\prime}\left(\eta^{\mathrm{n}}\right.\right.$-ring $) \mathrm{M}^{\prime}=$ $\left(\eta^{5}-\mathrm{C}_{5} \mathrm{Me}_{5}\right) \mathrm{Rh}, \quad\left(\eta^{6}-\mathrm{C}_{6} \mathrm{Me}_{6}\right) \mathrm{Ru}$ or $\left(\eta^{6}-p\right.$-cymene $) \mathrm{Ru}$; substrate $=$ methacrolein or $\alpha-\beta$ insaturated ketones) has been identified as active and selective catalysts in asymmetric Diels-Alder processes [1]. In these cases, weak intra-molecular interactions of the type $\mathrm{CH} / \pi$ has been identified as responsible for the remarked obtained stereoselectivity. Furthermore, a related group of complexes $\quad\left[\left(\eta^{\mathrm{n}} \text {-ring }\right) \mathrm{Ru}(\mathrm{POH})\right]^{+\mathrm{n}} \quad(\mathrm{POH}$ : $\left.\left.\left.\left(S_{\mathrm{Cl}}, R_{\mathrm{C} 2}\right)-\mathrm{Ph}_{2} \mathrm{PC}\right) \mathrm{Ph}\right) \mathrm{HC}(\mathrm{OH})-\mathrm{HCH}_{2} \mathrm{OMe}\right)$ have also showed intrinsic catalytic properties both in Diels-Alder and Friedel-Crafts processes. For these species, the structural studies have shown how the different alternative coordination modes $\kappa^{1} \mathrm{P}, \kappa^{2} \mathrm{P}, \mathrm{O}$ y $\kappa^{3} \mathrm{P}, \mathrm{O}, \mathrm{O}^{\prime}$ for the $\mathrm{POH}$ ligand increased the acid properties of the hydroxyl group and have given us clues to rationalize their different activities as Brönsted-acid catalyst through formation of inter-molecular hydrogen bonds. [2]

\section{References}

[1] A. Becerra, R. Contreras, D. Carmona, F.J. Lahoz, P. García-Orduña, Dalton Trans., 2013, 42, 11640-11651; D. Carmona, F. Viguri, A. Asenjo, F.J. Lahoz, P. García-Orduña, L. A. Oro, J. Mol. Cat. A, 2014, 385, 119-124 and references therein. [2] D. Carmona, M. P. Lamata. P. Pardo, R. Rodríguez, F.J. Lahoz, P. García-Orduña, I. Alkorta L.A. Oro, Organometallics, 2014, 33, 616-619 and 6927-6936.

Keywords: Molecular Structure, Catalytic Properties, Interatomic Interactions, Enantioselectivity

\section{MS31-O3 Novel 1-D rhodium polymeric chain systems via rhodium-rhodium interactions}

\author{
Carla Pretorius ${ }^{1}$, Alice Brink ${ }^{1}$, Andreas Roodt ${ }^{1}$
}

1. University of the Free State, Bloemfontein, South Africa, 9300

email: cpretorius87@gmail.com

Of interest to our research is the addition of metallophilic interactions to the arsenal library in the design of directionally orientated systems. The design of such systems has been highly motivated by the need for tuneable materials with unique magnetic, conducting, vapochromic and other properties that falls within a unique class of crystal engineering.

Metallophilic interactions occur when overlap arises between filled nd-orbitals, ns and np orbitals of transition metals such as gold, platinum, silver and rhodium. By facilitating these interactions metal centres are connected along one direction to form infinite 1-D metal chains. In our research, rhodium(I) complexes containing $\beta$-diketonato ligands were investigated for metallophilic interactions. A wide range of complexes were investigated with $\left[\mathrm{Rh}(\mathrm{acac})(\mathrm{CO})_{2}\right]$ systems $(\mathrm{acac}=$ acetylacetone) displaying short $\mathrm{Rh} \bullet \bullet \mathrm{Rh}$ interactions of 3.254(3) and 3.274(3) $\AA$ to complexes such as $\left[\mathrm{Rh}\left(4 \mathrm{Cl}-\mathrm{F}_{3}\right.\right.$ bzac $\left.)(\mathrm{CO})_{2}\right] \quad\left(4 \mathrm{Cl}-\mathrm{F}_{3}\right.$ bzac $=$ 1-(4-chlorophenyl)-4,4,4-trifluoro-1,3-butanedione) that contains ligands with greater steric bulk with Rh-Rh distances of 3.469(3) and 3.617(3) $\AA$.

The tailoring of ligand systems by altering electronic and steric properties allowed the manipulation of the metallophilic interactions which in turn resulted in altered physical properties of the materials. Additionally, it was observed that different crystallization conditions could result in changes in the assembly of molecules as illustrated with the isolated polymorph of $\left[\mathrm{Rh}\left(4 \mathrm{Cl}-\mathrm{F}_{3}\right.\right.$ bzac $\left.)(\mathrm{CO})_{2}\right]$ that displayed less diverse Rh-Rh distances of 3.523(3) and 3.593(3) A. Several novel rhodium complexes will be presented that displayed these unique metallophilic interactions. In addition, solution studies involving IR, UV/Vis and NMR that could evaluate induced stacking in solution by varying concentration and solvent choices will also be highlighted. 